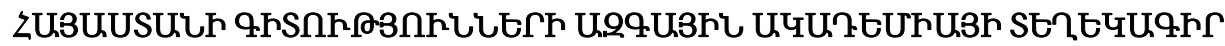 ИЗВЕСТИЯ НАЦИОНАЛЬНОЙ АКАДЕМИИ НАУК АРМЕНИИ
}

\author{
Uthuubhluw \\ УДК 539.3 \\ 71, №3, 2018 \\ Механика

\section{THE FORMATION AND PROPAGATION OF ELASTIC (SH) SHEAR WAVES IN A CELLULAR COMPOSITE WAVEGUIDE}

\author{
Ara S. Avetisyan, Vazgen M. Khachatryan \\ Keywords: composite waveguide, shear wave, wave energy localization, periodic structure, periodic \\ nonhomogeneous layer, forbidden frequencies, phase velocity, cellular composite.
}

Аветисян А.С., Хачатрян В.М.

Образование и распространение упругих (SH) сдвиговых волн в сетчатом композитном волноводе Ключевые слова: композитный волновод, сдвиговая волна, локализация волновой энергии, периодическая структура, неоднородный слой, запретные частоты, фазовая скорость, сетчатый композит.

Обсуждаются возможные варианты образования и распространения упругой сдвиговой волны в сетчатом композитном волноводе с каноническими прямоугольными ячейками. Сетчатый композитный волновод моделируется как слоистый волновод из периодически продольно неоднородных упругих слоёв. Получены и исследованы дисперсионные уравнения фильтрации частот вдоль волновода, а также дисперсионные уравнения формообразования в периодических прослойках, по толщине волновода. Показывается, что надлежащим выбором пар материалов в слоях периодической структуры, а также относительных толщин этих слоёв, можно достичь разных схем волнообразования по толщине композитного волновода.

Численно исследованы длинноволновое (низкочастотное) и коротковолновое (высокочастотное) приближения дисперсионных уравнений. Фононная структура составляющих слоёв волновода приводит к разным зонам пропускания частот, образуя фильтр по отдельным слоям. Локализованные ультракороткие медленные упругие сдвиговые волны по границам сопредельных композитных слоёв не распространяются. Локализация энергии упругой сдвиговой смежной волны (волна типа Лява) у границ сопредельных ячеек характеризуется модулями физических постоянных материалов и отношением длины образованной волны с толщинами составных слоёв.

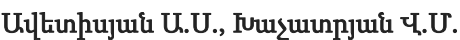

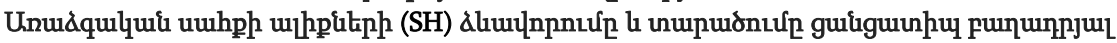
urhpuununntu

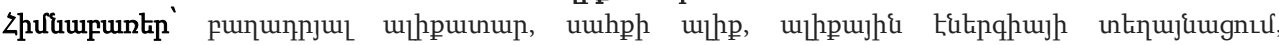

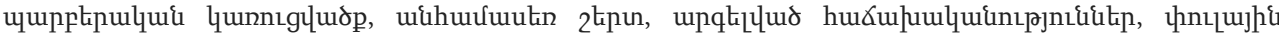

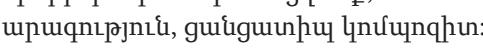

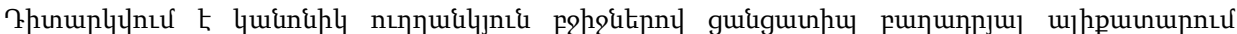

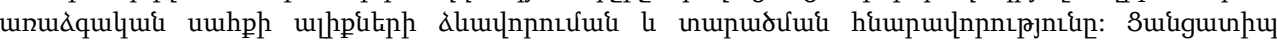

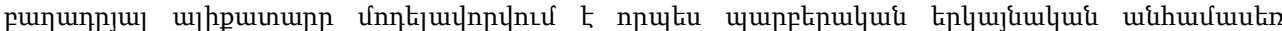

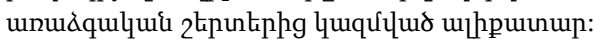

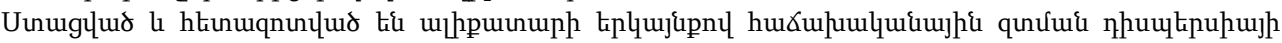

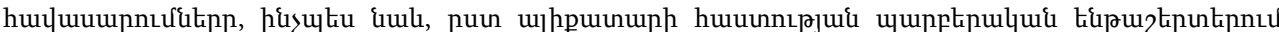

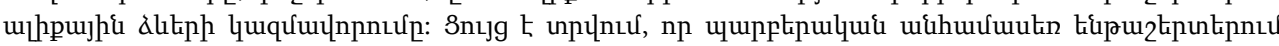

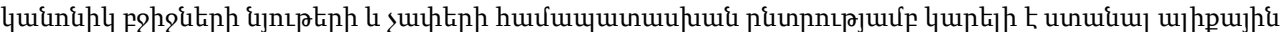

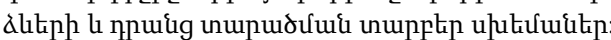

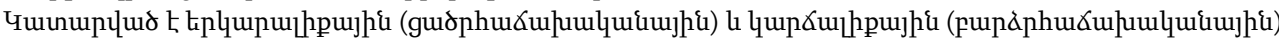

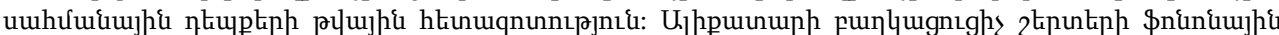

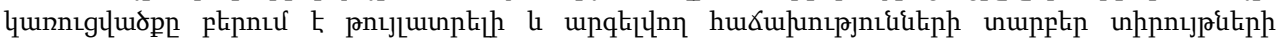




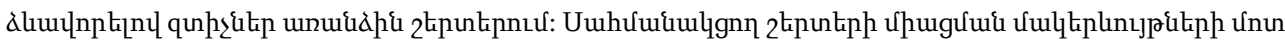

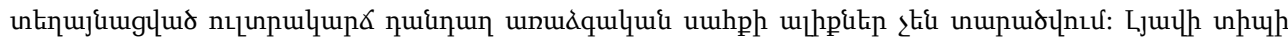

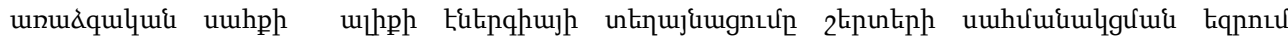

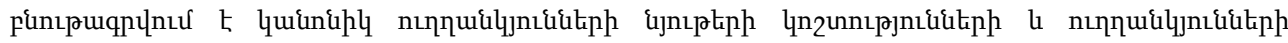

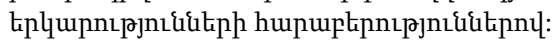

The cellular composite waveguide is modeled as a layered waveguide of periodically longitudinally inhomogeneous elastic layers. The dispersion equations of frequencies filtering in periodically inhomogeneous layers, as well as the dispersion equations of wave formation in the composite stratums are obtained and analyzed. It is shown, that through the proper selections of pairs of materials in the layers of periodic structure, as well as of the relative thicknesses of these stratums, different schemes of wave shaping on thickness of the composite waveguide can be obtained.

Long wavelength (low frequency) and shortwave (high frequency) approximations of the dispersion equations are numerically examined. A phononic structures of composing layers of the waveguide leads to different zones of the bandwidth of frequencies forming a filter in the separate layers. The localized ultra-short slow elastic shear waves by the borders of the adjacent composite layers don't propagate. The localization of energy of adjacent elastic shear wave (Love type waves) at the borders of neighboring cells is characterized by the modules of physical constants of materials as well as by the ratio of length of the waves to the thicknesses of the composite layers.

\section{Introduction.}

Dispersions and/or dissipations in the propagation of a normal wave signal in a homogeneous, bounded elastic medium depends strictly on the boundary conditions, on the physico-mechanical characteristics of the neighboring media. The possibility of localization of the wave energy of plane strain in the surface zone of a mechanically free surface of an elastic isotropic half-space is already shown in the primary source of research on the possible localization of wave energy in the propagation of waves Rayleigh J.W. [1] (Rayleigh wave1885г.).

In 1911 Love A. E. H. [2] showed that it is possible to localize the wave energy of the elastic shear in the near-surface zone of joining an elastic half-space with a softer elastic layer. After some time, in 1924 Stoneley R. [3] showed the possibility of localization of the wave energy of an elastic plane deformation in the near-surface contact zone of two isotropic elastic halfspaces if the densities and elastic modules of the boundary media differ insignificantly. In each of these cases, the wave formation along the thickness of composite structures is characterized by a phase bond of the length of the formed wave from the source oscillation frequency $-\lambda(\omega)$ (or by convenience, the correspondence of frequency and length of the formed wave $-\omega(\lambda))$. In all these and other classical problems, the phase relationship, in addition to the relative values of the physico-mechanical constants of the adjoining media, also depends on the nature of the surface conditions at the joint boundaries of the contiguous bodies.

The survey of the most widely used methods for determining the structure of eigenmodes propagating in periodic structures or the features of wave formation in different composite structures are presented in particular in Auld's B.A.[4], Achenbach's J. D. [5], Meleshko's V. V. etal.[6], Gazalet's J. etal. [7] works etc.

In recent years with the development of precise instrumentation, wave phenomena associated with stratification of waveguides have been widely studied. In the scientific literature one can find many works devoted to wave processes in transversely inhomogeneous waveguides or in longitudinally inhomogeneous waveguides. An extensive technical overview of the latest achievements (more than 400 titles) in the field of problems of the dynamics of elastic and electro-acoustic waves in periodic structures is given in M.I.Husseinetal's [8] work. The inhomogeneity of a periodic interlayers predetermines the nature of the wave form by 
the thickness of the composite waveguide. The results of the investigation of the existence of the Love type waves of in a three-layer elastic half-space are given in Kaptsov A.V., Kuznetsov S.V. [9]. In the paper Avetisyan A.S., Belubekyan M.V., Ghazaryan K.B. [10], the authors are modeled the joining of two half-spaces, withe the canonical rectangular projections, as a three-layer periodically inhomogeneous waveguide.

he proposed article discusses possible options for the formation and propagation of an elastic shear wave in a cellular composite waveguide. The cellular waveguide is modeled as a three-layer, longitudinally inhomogeneous elastic waveguide, consisting of periodically alternating composite inhomogeneous layers.

2. Modeling of a composite waveguide and formulation of the mathematical boundary value problem.

Three-layered waveguide consisting of the identically periodic longitudinally inhomogeneous layers, with thicknesses $2 h_{0}, 2 h_{1}$ and $2 h_{2}$ respectively, is represented by a composite inhomogeneous waveguide of general thickness $2 H=2\left(h_{0}+h_{1}+h_{2}\right)$ consisting of periodically alternating composite interlayers of elastic isotropic homogeneous materials (Fig. 1)

$$
\begin{aligned}
& \Omega_{n 2}(x ; y ; z)=\left\{a \leq x \leq b ;-2 h_{2}-h_{0} \leq y \leq h_{0}+2 h_{1} ;|z|<\infty\right\} \\
& \Omega_{n 1}(x ; y ; z)=\left\{0 \leq x \leq a ;-2 h_{2}-h_{0} \leq y \leq h_{0}+2 h_{1} ;|z|<\infty\right\}
\end{aligned}
$$

Unboundedness along the coordinate $z$ of the constituent layers of the waveguide allows to proceed to the two-dimensional formulation of the problem.

Each compound layer (2.1) and (2.2) in a periodic cell is formed from three, rectangular cells $\left\{m_{n m}(x ; y)\right\}$, ideally contacting on the internal surfaces of a layered waveguide $y= \pm h_{0}$

$\left\{m_{01}(x ; y)\right\}=\left\{0 \leq x \leq a ;-h_{0} \leq y \leq h_{0}\right\}$

$\left\{m_{02}(x ; y)\right\}=\left\{a \leq x \leq b ;-h_{0} \leq y \leq h_{0}\right\}$

$\left\{m_{11}(x ; y)\right\}=\left\{0 \leq x \leq a ; h_{0} \leq y \leq h_{0}+2 h_{1}\right\}$

$\left\{m_{12}(x ; y)\right\}=\left\{a \leq x \leq b ; h_{0} \leq y \leq h_{0}+2 h_{1}\right\}$

$\left\{m_{21}(x ; y)\right\}=\left\{0 \leq x \leq a ;-h_{0}-2 h_{2} \leq y \leq-h_{0}\right\}$

$\left\{m_{22}(x ; y)=\left\{a \leq x \leq b ;-h_{0}-2 h_{2} \leq y \leq-h_{0}\right\}\right\}$

the waveguide, and $m=1 ; 2$ are the numbers of distinguished composite interlayers in periodic cells.

In general, the materials in the isolated rectangular cells are different and, accordingly, are characterized by shear modules $G_{n m}$ and densities $\rho_{n m}$ of elastic materials. 


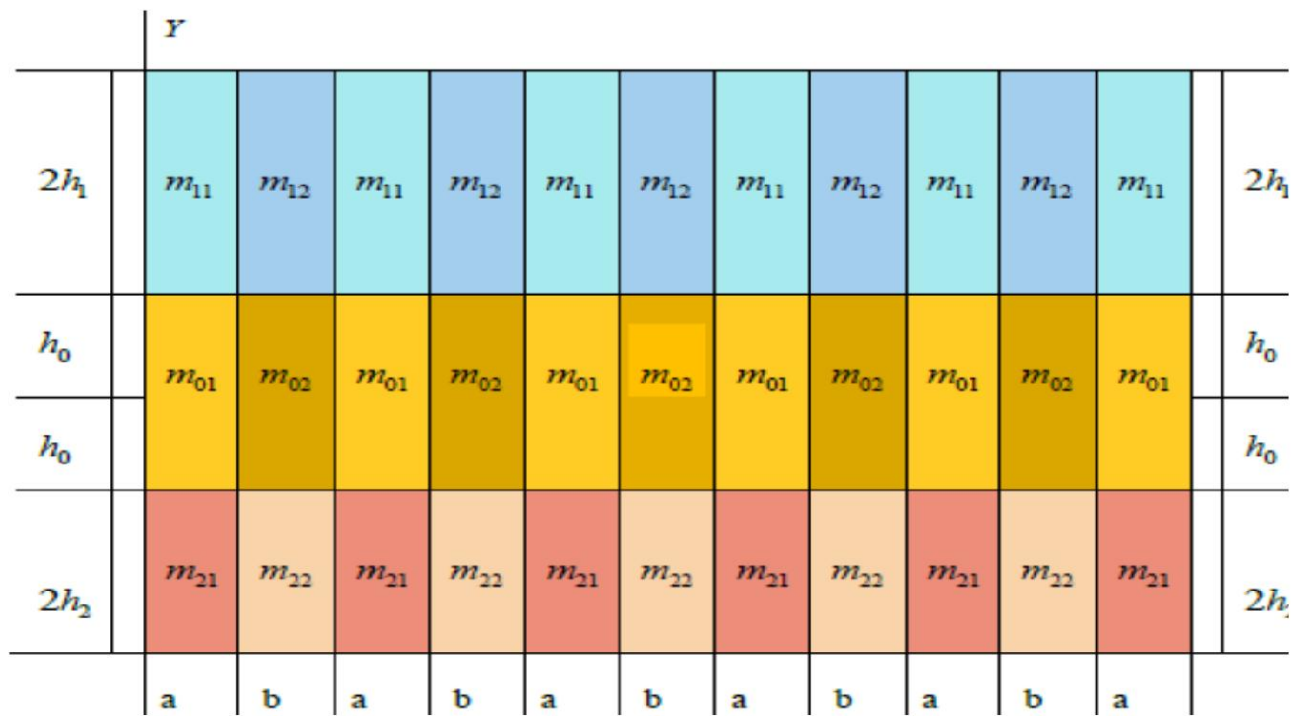

Fig. 1.1 The cellular structure of the periodically inhomogeneous three-layer elastic waveguide

where $n=0 ; 1 ; 2$ are the numbers of periodically inhomogeneous layers in if a flat normal (SH) wave signal of elastic shear $\mathrm{W}(x ; y ; t)=\mathrm{W}(x ; y) \cdot \exp (-i \omega t)$ is fed into the waveguide then along the formed three longitudinally inhomogeneous channels of the waveguide the interrelated elastic shear modes propagate. To study the patterns of wave propagation in a composite waveguide, rectangular cells will solve the wave equations of antiplane deformation In order to study the laws of wave propagation in composite waveguide the wave equations of the antiplane deformation will be solved in rectangular cells $\left\{m_{n m}(x ; y)\right\}$ :

$\frac{\partial^{2} \mathrm{w}_{n m}(x ; y)}{\partial x^{2}}+\frac{\partial^{2} \mathrm{w}_{n m}(x ; y)}{\partial y^{2}}=-\omega^{2} c_{n m}^{-2} \cdot \mathrm{w}_{n m}(x ; y)$,

where $c_{n m}=\sqrt{G_{n m} / \rho_{n m}}$ is the velocity of the volume shear wave in the material of the corresponding cell $\left\{m_{n m}(x ; y)\right\}$.

In each layer $n \in\{0 ; 1 ; 2\}$ on all the lateral surfaces of the adjacent interlayers, the conditions for complete mechanical contact are satisfied. On the section $x=a$, these conditions will be written in the known form:

$\mathrm{w}_{n 1}(a ; y ; t)=\mathrm{w}_{n 2}(a ; y ; t)$;

$G_{n 1} \cdot \partial \mathrm{w}_{n 1}(x ; y ; t) /\left.\partial x\right|_{x=a}=G_{n 2} \cdot \partial \mathrm{w}_{n 2}(x ; y ; t) /\left.\partial x\right|_{x=a}$

Taking into account the periodicity of the structure in the direction of wave propagation, the conditions for the conjugation of mechanical fields on the sections $x=0$ and $x=a+b$ are written in the form:

$\mathrm{w}_{n 1}(a+b ; y ; t)=\mu^{-1} \mathrm{w}_{n 2}(0 ; y ; t)$ 
$G_{n 1} \cdot \mu \cdot \partial \mathrm{w}_{n 1}(x ; y ; t) /\left.\partial x\right|_{x=a+b}=G_{n 2} \cdot \partial \mathrm{w}_{n 2}(x ; y ; t) /\left.\partial x\right|_{x=0}$

In the boundary conditions (2.8) $\mu=\exp (L k)$ is the Floquet multiplier (frequency coefficient) and $L=a+b$ is the linear parameter of periodicity. $k(\omega)=2 \pi / \lambda(\omega)-$ is the wave number of the formed wave (the Floquet wave number) corresponding to the permitted wavelengths $\lambda(\omega)$.

In all relations (in all three layers) (2.8) the Floquet multiplier is the same, because the canonical structure of the cellular waveguide leads to the same geometric periodicity in all three channels.

The conditions for complete mechanical contact are also satisfied on the contact surfaces of periodically inhomogeneous layers. Taking into account the periodicity of the waveguide structure, the conjugacy conditions of the mechanical fields on the inner surfaces $y=h_{0}$ and $y=-h_{0}$ of the waveguide will be written in the following form, respectively:

$$
\begin{aligned}
& \mathrm{w}_{01}\left(x ; h_{0} ; t\right)=\mathrm{w}_{11}\left(x ; h_{0} ; t\right) \\
& G_{01} \cdot \partial \mathrm{w}_{01}(x ; y ; t) /\left.\partial y\right|_{y=h_{0}}=G_{11} \cdot \partial \mathrm{w}_{11}(x ; y ; t) /\left.\partial y\right|_{y=h_{0}} \\
& \mathrm{w}_{01}\left(x ;-h_{0} ; t\right)=\mathrm{w}_{21}\left(x ;-h_{0} ; t\right) \\
& G_{01} \cdot \partial \mathrm{w}_{01}(x ; y ; t) /\left.\partial y\right|_{y=-h_{0}}=G_{21} \cdot \partial \mathrm{w}_{21}(x ; y ; t) /\left.\partial y\right|_{y=-h_{0}} \\
& \mathrm{w}_{02}\left(x ; h_{0} ; t\right)=\mathrm{w}_{12}\left(x ; h_{0} ; t\right) \\
& G_{02} \cdot \partial \mathrm{w}_{02}(x ; y ; t) /\left.\partial y\right|_{y=h_{0}}=G_{12} \cdot \partial \mathrm{w}_{12}(x ; y ; t) /\left.\partial y\right|_{y=h_{0}} \\
& \mathrm{w}_{02}\left(x ;-h_{0} ; t\right)=\mathrm{w}_{21}\left(x ;-h_{0} ; t\right) \\
& G_{02} \cdot \partial \mathrm{w}_{02}(x ; y ; t) /\left.\partial y\right|_{y=-h_{0}}=G_{22} \cdot \partial \mathrm{w}_{22}(x ; y ; t) /\left.\partial y\right|_{y=-h_{0}}
\end{aligned}
$$

On the external mechanically free surfaces $y=h_{0}+2 h_{1}$ and $y=-h_{0}-2 h_{2}$ of the waveguide, the boundary conditions are written in the following form, respectively:

$$
\begin{array}{ll}
\partial \mathrm{w}_{11}(x ; y ; t) /\left.\partial y\right|_{y=h_{0}+2 h_{1}}=0 ; & \partial \mathrm{w}_{12}(x ; y ; t) /\left.\partial y\right|_{y=h_{0}+2 h_{1}}=0 \\
\partial \mathrm{w}_{21}(x ; y ; t) /\left.\partial y\right|_{y=-h_{0}-2 h_{2}}=0 ; & \partial \mathrm{w}_{22}(x ; y ; t) /\left.\partial y\right|_{y=-h_{0}-2 h_{2}}=0
\end{array}
$$

\section{Solution of the mathematical boundary value problem.}

Taking into account the identical periodicity of all three layers (channels) of the waveguide and 2the invariance of the systems of equations (1.6) in all cells of the cellular waveguide, we construct the solution of the boundary value problem by the method of separation of variables $\mathrm{w}_{n m}(x ; y)=X_{n m}(x) \cdot Y_{n m}(y)$. We obtain six systems of ordinary differential equations:

$$
\left\{\begin{array}{l}
d^{2} X_{n m}(x) / d x^{2}+k_{n m}^{2} \cdot X_{m}(x)=0 \\
d^{2} Y_{n m}(y) / d y^{2}-k_{n m}^{2} \alpha_{n m}^{2} \cdot Y_{n m}(y)=0
\end{array}\right.
$$

Each system of equations (3.1) describes the state of the cell $\left\{m_{n m}(x ; y)\right\}$, where $n=0 ; 1 ; 2$ are the numbers of the layers in the waveguide and $m=1 ; 2$ are the numbers 
of the interlayers in the periodic cells, $\alpha_{n m}=\sqrt{1-\omega^{2} / k_{n m}^{2} c_{n m}^{2}}$ are the wave formation coefficients in the corresponding cells, $k_{n m}(\omega)$ is the wave number in the given cell.

The integrity of the wave process and the interconnection of wave formation along the thickness of the composite waveguide is ensured by the synchronism of the propagation of waves in the corresponding adjacent rectangular cells of the selected interlayers $m=1 ; 2$. Therefore, the solutions of the first equations of all six systems (3.1) in periodically longitudinally inhomogeneous channels $n \in\{0 ; 1 ; 2\}$ are written as harmonic functions:

$$
X_{n m}(x)=C_{n m} \sin \left(k_{m} x\right)+D_{n m} \cos \left(k_{m} x\right)
$$

For convenience in the analysis of the problem of localization of high-frequency waves, the solutions of the second equations of systems (3.1) will be written down by hyperbolic functions. Then the wave field in each cell of the composite waveguide will be written in the form

$$
\mathrm{w}_{n m}(x ; y ; t)=X_{n m}(x) \cdot\left[A_{n m} \cdot \operatorname{sh}\left(k_{m} \alpha_{n m} y\right)+B_{n m} \cdot \operatorname{ch}\left(k_{m} \alpha_{n m} y\right)\right] \cdot \exp (-i \omega t)
$$

Taking into account the same periodicity of all three layers of the waveguide, we use the Floquet-Lyapunov theory.

Substituting the solutions in the cells of a periodic cell (interlayers numbered $m=1 ; 2$ )

$\mathrm{w}_{n 1}(x ; y ; t)=\left[C_{n 1} \sin \left(k_{1} x\right)+D_{n 1} \cos \left(k_{1} x\right)\right] \times$

$\times\left[A_{n 1} \cdot \operatorname{sh}\left(k_{1} \alpha_{n 1} y\right)+B_{n 1} \cdot \operatorname{ch}\left(k_{1} \alpha_{n 1} y\right)\right] \cdot \exp (-i \omega t)$

$\mathrm{w}_{n 2}(x ; y ; t)=\left[C_{n 2} \sin \left(k_{2} x\right)+D_{n 2} \cos \left(k_{2} x\right)\right] \times$

$\times\left[A_{n 2} \cdot \operatorname{sh}\left(k_{2} \alpha_{n 2} y\right)+B_{n 2} \cdot \operatorname{ch}\left(k_{2} \alpha_{n 2} y\right)\right] \cdot \exp (-i \omega t)$

into the conditions of complete mechanical contact on the face of the cells, taking into account the periodicity of the channel structures (2.7) and (2.8), for nontrivial wave distributions in periodic composite interlayers we obtain three dispersion filtration equations for each layer by the number $n$

$\left\{\cos \left(L k_{n}^{*}\right)\right\}=\left\{\cos \left(k_{1} a\right) \cdot \cos \left(k_{2} b\right)-\frac{G_{n 1}^{2} k_{1}^{2}+G_{n 2}^{2} k_{2}^{2}}{2 G_{n 1} k_{1} G_{n 2} k_{2}} \sin \left(k_{1} a\right) \cdot \sin \left(k_{2} b\right)\right\}$

Each of these equations $n \in\{0 ; 1 ; 2\}$ corresponds to one of the channels in a three-layer waveguide. From each equation (3.5) the solvable wavelengths are determined, with the corresponding bands of admissible (or forbidden) frequencies

$\lambda_{n}^{*}(\omega)=2 \pi L / \arccos \left\{\cos \left(k_{1} a\right) \cdot \cos \left(k_{2} b\right)-A \times \sin \left(k_{1} a\right) \cdot \sin \left(k_{2} b\right)\right\}$

where $A=\left[G_{n 1}^{2} k_{1}^{2}(\omega)+G_{n 2}^{2} k_{2}^{2}(\omega)\right] /\left[2 G_{n 1} k_{1}(\omega) \cdot G_{n 2} k_{2}(\omega)\right]$

The solvable wave numbers determined in each channel (in layer with number $n \in\{0 ; 1 ; 2\}) k_{0}^{*}(\omega), k_{1}^{*}(\omega)$ and $k_{2}^{*}(\omega)$, and also the corresponding zones of admissible frequencies must be matched by the condition of synchronous propagation over the interlayers. The wave number $k(\omega)=2 \pi / \lambda(\omega)$ (wave number of Floquet) of the 
formed wave corresponding to the admissible frequencies $\omega$ is already defined as the cross section of the sets over the entire composite waveguide

$$
\{k(\omega)\}=\left\{k_{0}^{*}(\omega)\right\} \cap\left\{k_{1}^{*}(\omega)\right\} \cap\left\{k_{2}^{*}(\omega)\right\}
$$

It is obvious from (3.7) that the multilayer reduces the region of admissible frequencies. The measure of reduction depends on the difference in the physico-mechanical characteristics of the materials and the linear dimensions of the neighboring cells (see Fig. 3.a, 3.b and 6).

At first glance, from (3.5) and (3.6) it follows that the filtration property of a composite waveguide is mainly determined by the parameters of the longitudinal inhomogeneity $G_{n 1}$, $G_{n 2}, a$ and $b$. But, as it turns out later, the filtering features in the composite waveguide are determined by the composite nature of the periodic layers. The composition of materials and the linear dimensions of the cells in the interlayers determine the character of the formed waveform $k_{m}(\omega)$ in the interlayers. Wave numbers $k_{1}(\omega)$ and $k_{2}(\omega)$ in the corresponding interlayers of a periodic cell are determined from the boundary value problems formed in these composite interlayers.

Substituting the solutions of (3.4) of the second equations of the systems (3.1) of the corresponding cells, $\left\{m_{n 1}(x ; y)\right\}$, where $n \in\{0 ; 1 ; 2\}$, into the boundary conditions (2.9), (2.10), the first of (2.13) and the first of (2.14), and the solutions of the corresponding cells $\left\{m_{n 2}(x ; y)\right\}$, where $n \in\{0 ; 1 ; 2\}$, into the boundary conditions (2.11), (2.12), the second of (2.13) and the second of (2.14), we obtain two dispersion equations of wave formation characterizing the distributions of nontrivial solutions along the thickness of the interlayers $\Omega_{n 1}(x ; y ; z)$ and $\Omega_{n 2}(x ; y ; z)$ of the composite waveguide in general form:

$$
\operatorname{th}\left(2 \alpha_{0 m} k_{m} h_{0}\right)=\frac{\mu_{0 m}^{1 m} \cdot \operatorname{th}\left(2 \alpha_{1 m} k_{m} h_{1}\right)+\mu_{0 m}^{2 m} \cdot \operatorname{th}\left(2 \alpha_{2 m} k_{m} h_{2}\right)}{1+\mu_{0 m}^{1 m} \operatorname{th}\left(2 \alpha_{1 m} k_{1 m} h_{1}\right) \cdot \mu_{0 m}^{2 m} \operatorname{th}\left(2 \alpha_{2 m} k_{m} h_{2}\right)}
$$

In the dispersion equations of the wave formations (3.8) $k_{1}(\omega)$ and $k_{2}(\omega)$ are the desired wave numbers in the corresponding interlayers of the periodic waveguide cell, $\alpha_{n m} \triangleq \sqrt{1-\omega^{2} /\left(k_{m}^{2}(\omega) c_{n m}^{2}\right)}$ are the attenuation coefficients of the slow waves in the corresponding waveguide cell $\left\{m_{n m}(x ; y)\right\}, \quad \mu_{0 m}^{1 m} \triangleq G_{1 m} \alpha_{1 m} / G_{0 m} \alpha_{0 m} \quad$ and $\mu_{0 m}^{2 m} \triangleq G_{2 m} \alpha_{2 m} / G_{0 m} \alpha_{0 m}$ are the characteristic relative coefficients of the slow waves.

By the definition of the wave numbers $k_{1}(\omega)$ and $k_{2}(\omega)$ from equations (3.8), in fact, we determine the phase velocities $V_{\phi m}(\omega)=\omega / k_{m}(\omega)$ and shapes of the formed wave in each periodic composite layer of the waveguide when the wave signal passes with the frequency $\omega$.

By substituting the obtained values $k_{1}(\omega)$ and $k_{2}(\omega)$ into the dispersion equations (3.5) characterizing the passage of waves, at $n=\{0 ; 1 ; 2\}$, we obtain zones of admissible (or 
forbidden) frequencies $\left\{k_{0}^{*}(\omega)\right\},\left\{k_{1}^{*}(\omega)\right\}$ and $\left\{k_{2}^{*}(\omega)\right\}$ for each channel (along the periodically longitudinally inhomogeneous layer). The zones of admissible (or forbidden) frequencies $\{k(\omega)\}$ of the cellular composite waveguide are obtained from the relation (3.7).

It should be noted that the dispersion equations of the formations (3.8) in the above form correspond to slow $\boldsymbol{S H}$ elastic-shear waves when the phase velocity of the formed wave satisfies the condition $V_{m \phi}(\omega)=\omega^{2} / k_{m}^{2}(\omega)<\min _{n=0 ; 1 ; 2}\left\{c_{n m}^{2}\right\}$ in each interlayer. For waves of other characteristic types, the dispersion equations of the formations (3.8) are respectively transformed. In the case of studying of the propagation of fast waves: - with phase velocities $V_{m \phi}(\omega)=\omega^{2} / k_{m}^{2}(\omega) \geq \max _{n=0 ; 1 ; 2}\left\{c_{n m}^{2}\right\}, \quad$ or adjacent waves - with phase velocities $\min _{n=0 ; 1 ; 2}\left\{c_{n m}^{2}\right\} \leq V_{m \phi}(\omega)<\max _{n=0 ; 1 ; 2}\left\{c_{n m}^{2}\right\} \quad$ in the layers of the composite waveguide the dispersion equations of the formations (3.8) are respectively transformed to the following form:

$$
\operatorname{tg}\left(2 \beta_{0 m} k_{m} h_{0}\right)=\frac{v_{0 m}^{1 m} \cdot \operatorname{tg}\left(2 \beta_{1 m} k_{m} h_{1}\right)+v_{0 m}^{2 m} \cdot \operatorname{tg}\left(2 \beta_{2 m} k_{m} h_{2}\right)}{1-v_{0 m}^{1 m} \cdot \operatorname{tg}\left(2 \beta_{1 m} k_{1 m} h_{1}\right) \cdot v_{0 m}^{2 m} \cdot \operatorname{tg}\left(2 \beta_{2 m} k_{m} h_{2}\right)}
$$

where $v_{0 m}^{1 m} \triangleq G_{1 m} \beta_{1 m} / G_{0 m} \beta_{0 m}$ and $v_{0 m}^{2 m} \triangleq G_{2 m} \beta_{2 m} / G_{0 m} \beta_{0 m}$ - characteristic relative coefficients of fast waves. In the case of studying of the propagation of adjacent waves, for which the phase velocities in periodic interlayers in different ratios with the space velocities in the cells $\min _{n=0 ; 1 ; 2}\left\{c_{n m}^{2}\right\} \leq V_{m \phi}(\omega)<\max _{n=0 ; 1 ; 2}\left\{c_{n m}^{2}\right\}$, the dispersion equations of the formations (3.8) are respectively transformed to the form:

$$
\operatorname{tg}\left(2 \beta_{0 m} k_{m} h_{0}\right)=\frac{\delta_{0 m}^{1 m} \cdot \operatorname{th}\left(2 \alpha_{1 m} k_{m} h_{1}\right)+\delta_{0 m}^{2 m} \cdot \operatorname{th}\left(2 \alpha_{2 m} k_{m} h_{2}\right)}{\delta_{0 m}^{1 m} \operatorname{th}\left(2 \alpha_{1 m} k_{1 m} h_{1}\right) \cdot \delta_{0 m}^{2 m} \cdot \operatorname{th}\left(2 \alpha_{2 m} k_{m} h_{2}\right)-1}
$$

where $\delta_{0 m}^{1 m} \triangleq G_{1 m} \alpha_{1 m} / G_{0 m} \beta_{0 m}$ and $\delta_{0 m}^{2 m} \triangleq G_{2 m} \alpha_{2 m} / G_{0 m} \beta_{0 m}$ - characteristic relative coefficients for adjacent waves.

From the inferential dispersion equations of formation $(3.8) \div(3.10)$ it is obvious that the existence of their respective solutions uniquely depends both on the relationships of the physical-mechanical characteristics of the materials and on the relative linear dimensions that make up the rectangular elements of the composite waveguide.

On the other hand, the obtained forms will propagate in the region determined from (3.5), (3.6) and (3.7).

It is clear that even in the case of a three-layered, periodic longitudinally inhomogeneous waveguide, there are many choices of different possible combinations and a group of materials and linear dimensions that make up the cellular waveguide of rectangular cells. In practice, many applied problems in which the achievement of the desired solution depends on the choice of different combinations of physical-mechanical characteristics of the materials of rectangular cells and/or the relative linear dimensions of the elements of the composite waveguide. Of course, this can be achieved by a machine choice. Here we will 
investigate the characteristic model cases of propagation of a wave signal in structures with known parameters.

\section{Model cases of propagation of shear wave signals in a three-layered} cellular waveguide.

For the convenience of studying the wave process, we represent the dispersion equations of the wave formation (3.8) in the form

$$
\operatorname{th}\left(2 \alpha_{0 m} k_{m} h_{0}\right)=\frac{\frac{G_{1 m} \alpha_{1 m}}{G_{0 m} \alpha_{0 m}} \cdot \operatorname{th}\left(2 \alpha_{1 m} k_{m} h_{1}\right)+\frac{G_{2 m} \alpha_{2 m}}{G_{0 m} \alpha_{0 m}} \cdot \operatorname{th}\left(2 \alpha_{2 m} k_{m} h_{2}\right)}{1+\frac{G_{1 m} \alpha_{1 m}}{G_{0 m} \alpha_{0 m}} \cdot \operatorname{th}\left(2 \alpha_{1 m} k_{m} h\right) \cdot \frac{G_{2 m} \alpha_{2 m}}{G_{0 m} \alpha_{0 m}} \cdot \operatorname{th}\left(2 \alpha_{2 m} k_{m} h_{2}\right)}
$$

where the factors (factors of the Love problem) like $\left(\operatorname{th}\left(2 \alpha_{j m} k_{m} h_{j}\right) / G_{j m} \alpha_{j m}\right)$ characterize the form of the wave in each layer.

Dispersion equations are easily derived from (4.1) in the limiting cases of the wave formation process: in the long-wave (low-frequency) and short-wave (high-frequency) approximations. In studies of limiting cases, we shall conventionally assume that in a three-layered cellular waveguide, the thickness of the inner inhomogeneous layer is either less $h_{0}<\min \left\{h_{1} ; h_{2}\right\}$ , or greater $h_{0}>\max \left\{h_{1} ; h_{2}\right\}$ than the thicknesses of the remaining two layers. In numerical calculations, these and other linear dimensions of the canonical rectangular cells will be taken in accordance with the requirements of the problem under study.

Table 1. Shear Modules, densities and velocities of shear waves in some good conductors and piezoelectric crystals

\begin{tabular}{|l|l|l|l|l|l|}
\hline & Gold Au & $\begin{array}{l}\text { Copper } \\
\mathrm{Cu}\end{array}$ & Silver Ag & PZT-4 & $\begin{array}{l}\text { Zinc } \\
\text { oxide } \\
\mathrm{ZnO}\end{array}$ \\
\hline $\begin{array}{l}\text { Shear module of the } \\
\text { material of cells } \\
G_{n m}\left(\mathrm{n} / \mathrm{m}^{2}\right)\end{array}$ & $2.7 \times 10^{10}$ & $4.833 \times 10^{10}$ & $3.03 \times 10^{10}$ & $2.56 \times 10^{10}$ & $4.25 \times 10^{10}$ \\
\hline $\begin{array}{l}\text { Density of the } \\
\text { material of the cells } \\
\rho_{n m}\left(\mathrm{~kg} / \mathrm{m}^{3}\right)\end{array}$ & $19.32 \times 10^{3}$ & $8.93 \times 10^{3}$ & $10.49 \times 10^{3}$ & $7.5 \times 10^{3}$ & $5.68 \times 10^{3}$ \\
\hline $\begin{array}{l}\text { Velocity of the } \\
\text { volume }(\mathrm{SH}) \text { wave } \\
c_{n m}(\mathrm{~m} / \mathrm{sec})\end{array}$ & $1.182 \times 10^{3}$ & $2.326 \times 10^{3}$ & $1.67 \times 10^{3}$ & $1.85 \times 10^{3}$ & $2.74 \times 10^{3}$ \\
\hline
\end{tabular}

Also, we will assume that the speed of volume shear waves in materials of rectangular cells $\left\{m_{0 m}(x ; y)\right\}$ of the inner layer is less than volume velocities of shear waves $C_{0 m}<\min \left\{C_{1 m} ; C_{2 m}\right\}$ or greater than the volume velocities of shear waves $C_{0 m}>\max \left\{C_{1 m} ; C_{2 m}\right\}$ in neighboring cells $m_{1 m}(x ; y)$ and $m_{2 m}(x ; y)$, respectively, 
where $m=1 ; 2$. Numerical analysis will be carried out by choosing different combinations of materials for contiguous cells of periodic layers from Table 1 .

4.a. Propagation of low-frequency shear waves (long waves) in a three-layered cellular waveguide.

In case of a low-frequency propagation of shear waves in a waveguide, long waves are formed for which $2 \pi h_{n} / \lambda_{m}(\omega) \ll 1$ or $k_{m}(\omega) \cdot h_{n} \ll 1$ for all values of $m \in\{1 ; 2\}$, $n \in\{0 ; 1 ; 2\}$. In this case, from (4.1) we obtain dispersion equations for the formation in periodic layers of the waveguide simplified by long-wave approximation:

$k_{m}^{4} h_{0}^{4}-\left[\left(\theta_{02 m}+\theta_{01 m}\right) \omega_{0}^{2}-q_{m}\right] \cdot k_{m}^{2} h_{0}^{2}+\left(\theta_{02 m} \theta_{01 m} \omega_{0}^{2}-p_{m}\right) \omega_{0}^{2}=0$

where

$$
q_{m}=\left(1-\delta_{10} \gamma_{10 m}-\delta_{20} \gamma_{20 m}\right) / 4 \delta_{10} \delta_{20} \gamma_{10 m} \gamma_{20 m}
$$

$p_{m}=\left(1-\delta_{10} \rho_{10 m}-\delta_{20} \rho_{20 m}\right) / 4 \delta_{10} \delta_{20} \gamma_{10 m} \gamma_{20 m}$ are the parameters of the waveguide that depend on the relative thicknesses of the layers composing the waveguide $\delta_{n 0}=h_{n} / h_{0}$ , the relative stiffness's of the shear $\rho_{n 0 m}=\rho_{n m} / \rho_{0 m}$ and the relative densities $\gamma_{n 0 m}=G_{n m} / G_{0 m}$, and $\theta_{0 n m}=c_{0 m}^{2} / c_{n m}^{2}$ is the ratio of the squares of the velocities of the volume waves of shear of the materials of the neighboring cells in the interlayers $m \in\{1 ; 2\}$ and $n \in\{0 ; 1 ; 2\}, \omega_{0}=\left(\omega h_{0} / c_{0 m}\right)$ is the dimensionless frequency normalized by the parameters of the inner layer of the waveguide. From the form of the dispersion equations for the formation (4.2) it follows that for the existence of two pairs of long waves with respect to the thickness of the inner thin layer of the waveguide $k_{m}(\omega) \cdot h_{0} \ll 1$, in each composite interlayer it is sufficient to require

$$
\left(\omega h_{0} / c_{0 m}\right)^{2}>\max \left\{\begin{array}{l}
\frac{1-\delta_{10} \rho_{10 m}-\delta_{20} \rho_{20 m}}{4 \delta_{10} \delta_{20} \rho_{10 m} \rho_{20 m}} ; \\
\frac{1-\delta_{10}-\delta_{20}\left(\gamma_{20 m} / \gamma_{10 m}\right)}{4 \delta_{10} \delta_{20}\left[\rho_{20 m}+\rho_{10 m}\left(\gamma_{20 m} / \gamma_{10 m}\right)\right]}
\end{array}\right\}
$$

Then, for the positive determinant of the biquadratic equation (4.2)

$$
\begin{aligned}
& \omega_{0}^{4}-2 \theta_{10 m} \theta_{20 m} \cdot\left[q_{m}-2 p_{m} /\left(\theta_{01 m}-\theta_{02 m}\right)^{2}\right] \cdot \omega_{0}^{2}+ \\
& +q_{m}^{2} /\left(\theta_{01 m}-\theta_{02 m}\right)^{2} \geq 0
\end{aligned}
$$

the formation of waves along the layers of the waveguide along with the condition (4.3) will depend on the presence of zones of the dimensionless frequency in a limited band of low frequencies 


$$
\left.\left(\omega h_{0} / c_{0 m}\right)^{2} \leq \theta_{10 m} \theta_{20 m} \times\left\{\sqrt{\left[q_{m}-\frac{2 p_{m}}{\left(\theta_{01 m}-\theta_{02 m}\right)^{2}}\right]-}\right]-\sqrt{\left[q_{m}-\frac{2 p_{m}}{\left(\theta_{01 m}-\theta_{02 m}\right)^{2}}\right]^{2}-\frac{\theta_{01 m}^{2} \theta_{02 m}^{2} \cdot q_{m}^{2}}{\left(\theta_{01 m}-\theta_{02 m}\right)^{2}}}\right\}
$$

or in a semi-restricted band of relatively high frequencies

$$
\left(\omega h_{0} / c_{0 m}\right)^{2} \geq \theta_{10 m} \theta_{20 m} \times\left\{\begin{array}{l}
{\left[q_{m}-\frac{2 p_{m}}{\left(\theta_{01 m}-\theta_{02 m}\right)^{2}}\right]+} \\
+\sqrt{\left[q_{m}-\frac{2 p_{m}}{\left(\theta_{01 m}-\theta_{02 m}\right)^{2}}\right]^{2}-\frac{\theta_{01 m}^{2} \theta_{02 m}^{2} \cdot q_{m}^{2}}{\left(\theta_{01 m}-\theta_{02 m}\right)^{2}}}
\end{array}\right\}
$$

The solutions of the dispersion equations for the shaping in both periodic layers of the waveguide (4.2) in a limited band of low frequencies $\{(4.3) ;(4.5) ;(4.6)\}$ will be written in the form

$$
k_{m}^{ \pm}(\omega)=\frac{1}{h_{0}}\left\{\begin{array}{l}
\frac{\left[\left(\theta_{01 m}+\theta_{02 m}\right) \omega_{0}^{2}-q_{m}\right]}{2} \\
\pm \sqrt{\frac{\left.\left[\theta_{01 m}+\theta_{02 m}\right) \omega_{0}^{2}-q_{m}\right]^{2}}{4}-\theta_{01 m} \theta_{02 m} \omega_{0}^{4}+p_{m} \omega_{0}^{2}}
\end{array}\right\}
$$

Substituting the obtained values of the wave numbers $k_{1}(\omega)$ and $k_{2}(\omega)$ into the dispersion equations of the channels (filtration equations) (3.5) and comparing the solutions with the frequency bands $\{(4.3) ;(4.5) ;(4.6)\}$, we find bands of admissible (or forbidden) frequencies through the channels $n \in\{0 ; 1 ; 2\}$. From (3.6) we also find admissible wavelengths $\lambda_{n}^{*}(\omega)$ through the channels $n \in\{0 ; 1 ; 2\}$. All the results obtained are related to the long-wave approximation. The results, that are in the approximation range $\operatorname{th}\left(2 \alpha_{n m} k_{m} h_{0}\right) \approx 2 \alpha_{n m} k_{m} h_{n}$ are suitable, with the corresponding channel numbers $n \in\{0 ; 1 ; 2\}$ and periodic interlayers $m \in\{1 ; 2\}$.

In order not to lose the effect of the periodic inhomogeneity of the waveguide, for long-wave approximations, it is necessary to take into account the correspondence of the linear parameters

$$
\left\{\begin{array}{l}
\left(\min _{n \in\{0 ; 1 ; 2\}}\left\{h_{n}\right\}\right) / \lambda_{m}(\omega) \ll 1 \\
\lambda_{m}(\omega) \leq \min \{a ; b\}
\end{array} \quad \Rightarrow\left(\min _{n \in\{0 ; 1 ; 2\}}\left\{h_{n}\right\}\right) / \min \{a ; b\} \ll 1\right.
$$


Consequently, the long-wavelength approximation is suitable for thin three-layer waveguides with a relatively large linear periodicity parameter $L=a+b$.

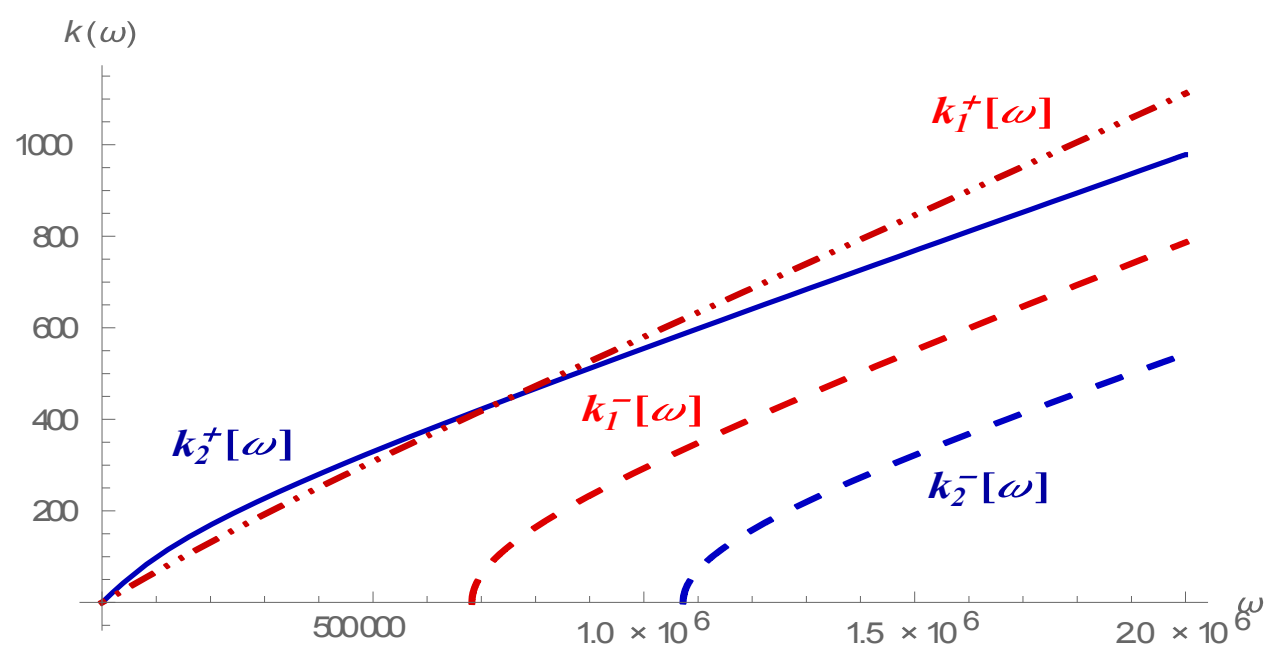

Fig. 2.a Wave numbers of wave formation in interlayers $k_{1}^{+}(\omega) \rightleftarrows\{C u+A u+Z n O\}$, $k_{2}^{+}(\omega) \rightleftarrows\{P Z T-4+A g+Z n O\}$ of the composite waveguide with a thick inner layer $h_{0}=1.0 \times 10^{-2} \mathrm{~m}, h_{1}=1.0 \times 10^{-3} \mathrm{~m}$ and $h_{2}=2.0 \times 10^{-3} \mathrm{~m}$. in the case of long-wave approximation.

In the first layer for the adjoining cells of copper $-c_{11}=2.326 \times 10^{3} \mathrm{~m} / \mathrm{sec}$, of gold $c_{01}=1.182 \times 10^{3} \mathrm{~m} / \mathrm{sec}$, of zinc oxide $-c_{21}=2.735 \times 10^{3} \mathrm{~m} / \mathrm{sec}$ and in the second layer of the piezoelectric crystal PZT-4 $-c_{12}=1.848 \times 10^{3} \mathrm{~m} / \mathrm{sec}$, of silver $c_{02}=1.67 \times 10^{3} \mathrm{~m} / \mathrm{sec}$ and of zinc oxide $-c_{22}=2.735 \times 10^{3} \mathrm{~m} / \mathrm{sec}$, in the frequency range $\omega \in\left[0 ; 10^{6}\right]$ Hertz, the dispersion equation for the formation (4.2) for each interlayer has two solutions (Fig. 2.a and Fig. 2.b).

Fig. 2.a shows the wave numbers for the formation in the case of a relatively thick (centimeter) inner layer of the waveguide.

From these graphs it follows that the lengths of the first two branches of the formed wave in the interlayers are above the centimeter thickness

$\left\{\lambda_{2 \min }^{+}(\omega) ; \lambda_{1 \min }^{+}(\omega)\right\} \geq h_{0}=1.0 \times 10^{-2} \mathrm{~m}$, up to the value of the frequency $\omega_{\text {min }}^{+}=1.0 \times 10^{6}$ Hertz.

The lengths of the second pair of branches of the formed wave, which are formed at relatively higher frequencies $\omega_{\text {min }}^{-}=0.8 \times 10^{6}$ Hertz in the interlayers remain above the centimeter thickness $\left\{\lambda_{2 \min }^{-}(\omega) ; \lambda_{1 \text { min }}^{-}(\omega)\right\} \geq h_{0}=1.0 \times 10^{-2} \mathrm{~m}$ at rather large values of the 
frequency $\omega_{\max }^{-} \approx 2.0 \times 10^{6} \div 2.5 \times 10^{6}$ Hertz.

Fig.2.b shows the wave numbers of the formation in the case of a relatively thin (millimeter) inner layer of the waveguide. In this case, two pairs of wave branches are also formed. From these graphs it follows that up to the value of the frequency $\omega_{\min }^{+}=1.0 \times 10^{6}$ Hertz the lengths of the first two branches of the formed wave in the interlayers are already at the limit of millimeter waves $\left\{\lambda_{2 \min }^{+}(\omega) ; \lambda_{1 \text { min }}^{+}(\omega)\right\} \approx 3.0 \times 10^{-3} \mathrm{~m}$.

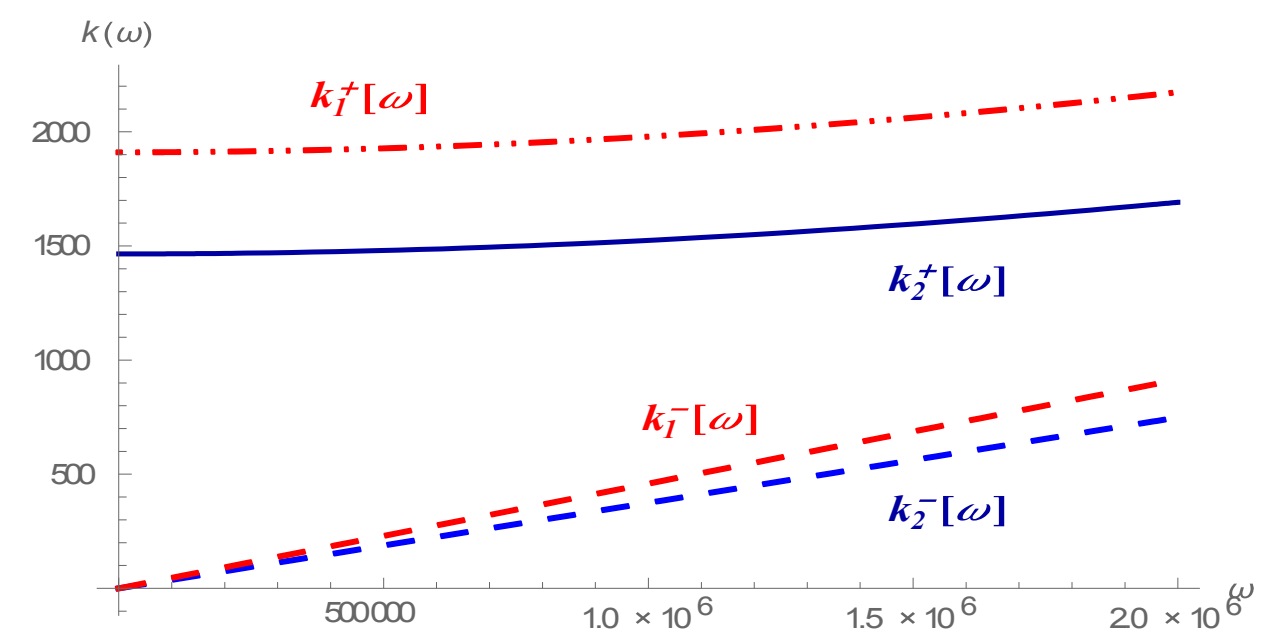

The lengths of the second pair of branches of the formed wave which are also formed at very low frequencies in interlayers remain above the millimeter

Fig. 2.b Wave numbers of wave formation in interlayers

$k_{1}^{+}(\omega) \rightleftarrows\{C u+A u+Z n O\}, k_{2}^{+}(\omega) \rightleftarrows\{P Z T-4+A g+Z n O\} \quad$ of the composite waveguide with a thin inner layer $h_{0}=1.0 \times 10^{-4} \mathrm{~m}, h_{1}=1.0 \times 10^{-3} \mathrm{~m}$ and $h_{2}=2.0 \times 10^{-3} \mathrm{~m}$. in the case of long-wave approximation.

thickness $\left\{\lambda_{2 \min }^{-}(\omega) ; \lambda_{1 \min }^{-}(\omega)\right\} \geq \max \left\{h_{1} ; h_{2}\right\}=2.0 \times 10^{-3} \mathrm{~m}$ also at rather large values of the frequency $\omega_{\max }^{-} \approx 2.5 \times 10^{6} \div 3.0 \times 10^{6}$ Hertz.

Comparative analysis indicates that for a given choice of boundary materials and different relative thicknesses of the waveguide layers, both millimeter and centimeter waves can be formed in the interlayers. From the point of view of the long-wave approximation of the widths of the cells (or interlayers) in each case of investigations the thicknesses of the layers $\{a ; b\} \sim \max \left\{h_{0} ; h_{1} ; h_{2} ; \lambda_{\max }(\omega)\right\}$ should be taken so as for the formed wavelengths $\lambda_{\text {max }}(\omega) \leq \min \{a ; b\}$. 
Then from the dispersion equation of the filtration (3.6) we find the lengths of the admissible waves, as well as the bands of permissible (and forbidden) frequencies along the channels of a periodically longitudinally inhomogeneous waveguide (Fig. 3.a and Fig. 3.b).

From the curves given in the figures 3.a and 3.b it follows that the transmitted waves with their zones of permissible and forbidden frequencies are formed both for a pair of branches of waves with smaller wave numbers $k_{m}^{-}(\omega)$ (red lines) and for a pair of branches of waves with larger wave numbers $k_{m}^{+}(\omega)$ (blue lines).

The zones of permissible frequencies for relatively short forms formed in this case are rather narrow. Joint zones of admissible frequencies in both cases of millimeter and centimeter waves are located in sections of the bands of permissible frequencies of the waveguide channels.

In the case of the given set of cell materials and their linear dimensions, the cross-section of the permissible zones is mainly related to the wavelength spectrum $\left\{\lambda_{\min }^{ \pm}(\omega) ; \lambda_{\max }^{ \pm}(\omega)\right\} \in[0 ; 10] m m$.

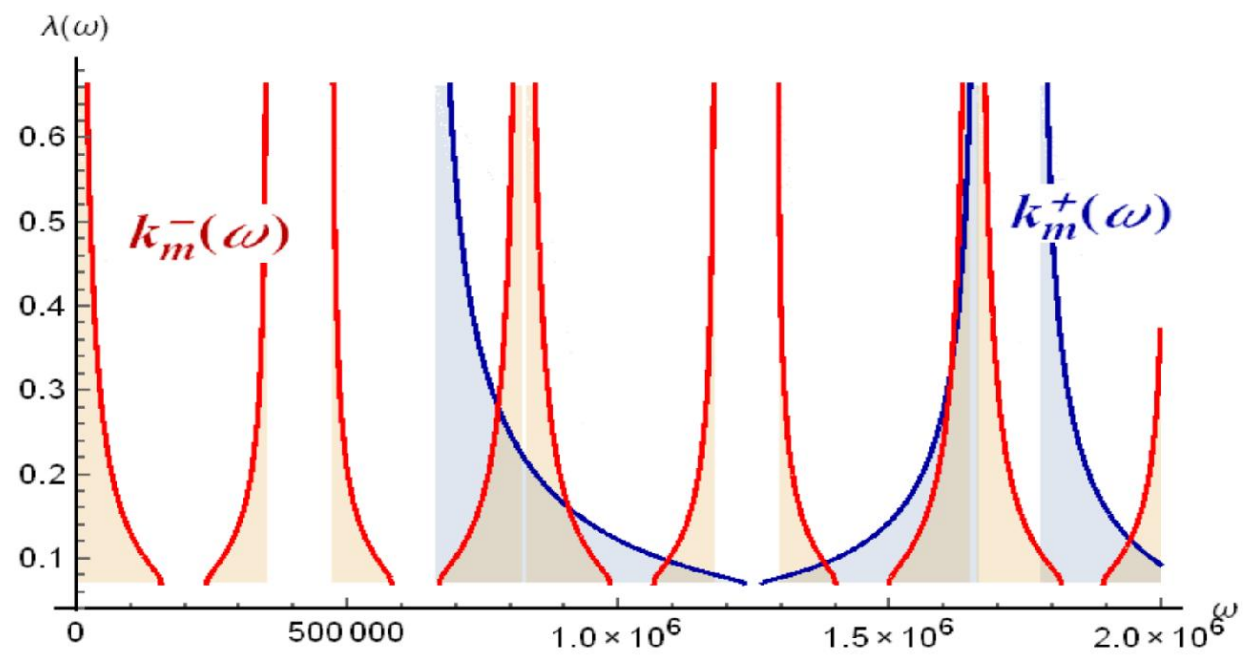

Fig.3a. The lengths of the permissible waves $\lambda(\omega)$ in the case of a millimeter inner layer of a composite waveguide $h_{0}=1.0 \times 10^{-4} \mathrm{~m}$ with the given wave numbers $k_{m}^{ \pm}(\omega)$

Zones of admissible frequencies of long centimeter waves appear immediately, even at lower frequencies (Fig.3.b). These zones and zones of forbidden frequencies are rather wide in comparison with the zones of long millimeter frequencies (Fig. 3.a). In the case of millimeter long waves, the bands of permissible frequencies for the relatively short formed forms are in the region of frequencies $\omega_{\min }^{+} \approx 6.0 \times 10^{5}$ Hertz (Fig.3.a). 


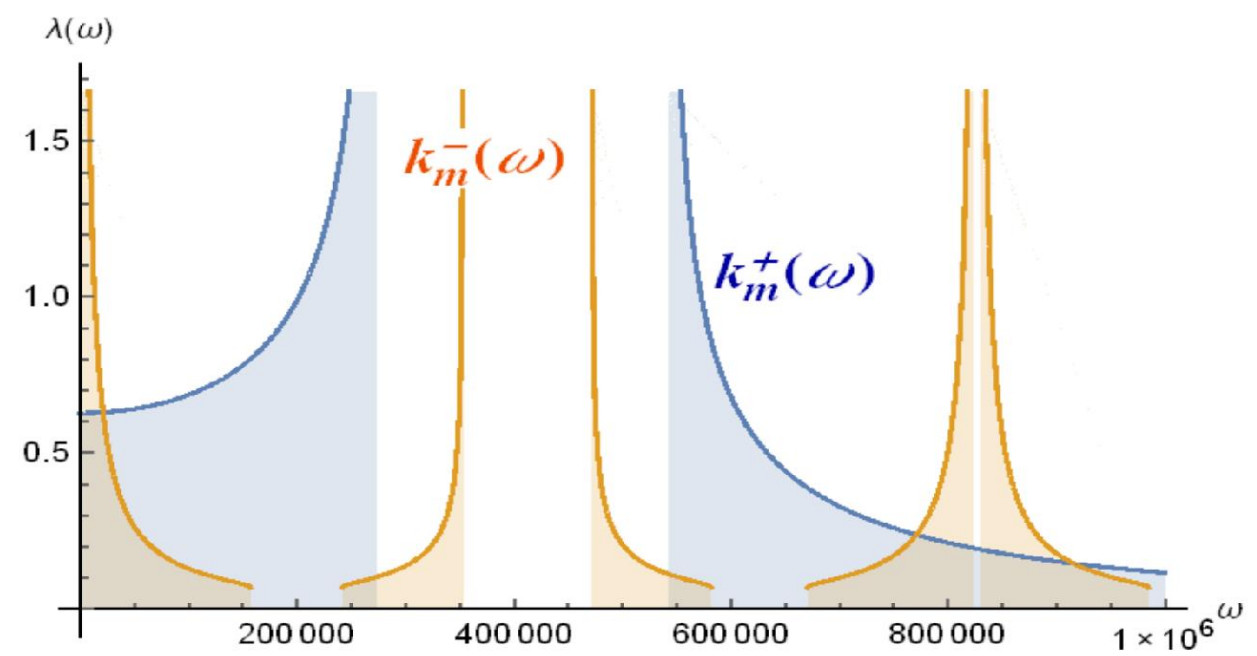

Fig. 3.b The lengths of permissible waves $\lambda(\omega)$ in the case of a centimeter inner layer of a composite waveguide $h_{0}=1.0 \times 10^{-2} \mathrm{~m}$. with the given wave numbers $k_{m}^{ \pm}(\omega)$ (Fig.2.a).

4.b. Propagation of high-frequency shear waves (short waves) in a three-layer cellular waveguide.

During the propagation of high-frequency shear wave signals, short waves are formed in the waveguide, for which $2 \pi h_{n} / \lambda_{m}(\omega) \gg 1$ for all values of the numbers of periodic interlayers $m \in\{1 ; 2\}$ and for waveguide channels $n \in\{0 ; 1 ; 2\}$. In this case, from equations (4.1) we obtain simplified dispersion equations for the formation in the shortwavelength approximation for both periodic layers of the waveguide $m \in\{1 ; 2\}$

$$
\begin{aligned}
& {\left[\gamma_{10 m}^{2} \theta_{01 m}+\gamma_{20 m}^{2} \theta_{02 m}-1-\theta_{01 m} \theta_{02 m}\right] \cdot \eta_{m}^{4}(\omega)+} \\
& +\left[\left(1-\gamma_{20 m}^{2} \theta_{02 m}\right)\left(1-\gamma_{10 m}^{2}\right)+\left(1-\gamma_{10 m}^{2} \theta_{01 m}\right)\left(1-\gamma_{20 m}^{2}\right)\right] \cdot \eta_{m}^{2}(\omega)+ \\
& +\left[\left(\gamma_{10 m}+\gamma_{20 m}\right)^{2}-\left(1+\gamma_{10 m} \gamma_{20 m}\right)^{2}\right]=0
\end{aligned}
$$

In addition to the notations adopted, in (4.8) we also introduced the notation for the normalized phase velocities in the interlayers $\eta_{m}(\omega)=\omega /\left(k_{m}(\omega) c_{0 m}\right)$.

From (4.8) it follows that the possible propagation of a high-frequency waves in a cellular waveguide, as well as the values of the phase velocities in periodic interlayers depend only on the relative physical-mechanical characteristics of the materials in the neighboring rectangular cells of the waveguide.

Here, the short-wavelength approximation (4.8) is given for the case of slow short waves, at $\alpha_{n m} k_{m} h_{n} \approx 2 \pi$. The taken approximation makes it possible to represent the phase velocities of possible high-frequency waveforms (and also the corresponding wave numbers) in the interlayers in the following form: 


$$
\begin{aligned}
& k_{m}(\omega)=\max _{n=0 ; 1 ; 2 ;}\left\{\left(\omega / c_{n m}\right) \cdot \sqrt{1+\left(2 \pi c_{n m} / h_{n} \omega\right)^{2}}\right\} ; \\
& V_{\phi m}(\omega)=\min _{n=0 ; 1 ; 2 ;}\left\{c_{n m} / \sqrt{1+\left(2 \pi c_{n m} / h_{n} \omega\right)^{2}}\right\}
\end{aligned}
$$

The obtained solutions of equations (3.9) in the interlayers $\eta_{m}(\omega)$ must satisfy the condition $\eta_{m}(\omega)=\min _{n=0 ; 1 ; 2 ;}\left\{\omega /\left(k_{m}(\omega) c_{n m}\right)\right\} \leq 1$

From the representation (4.9) we find the suitable values for the length of the waves formed in the interlayers, which will be short in all three layers of the waveguide

$$
\lambda_{m}(\omega)=\min _{n=0 ; 1 ; 2 ;}\left\{h_{n} / \sqrt{1+\left(h_{n} \omega / 2 \pi c_{n m}\right)^{2}}\right\}
$$

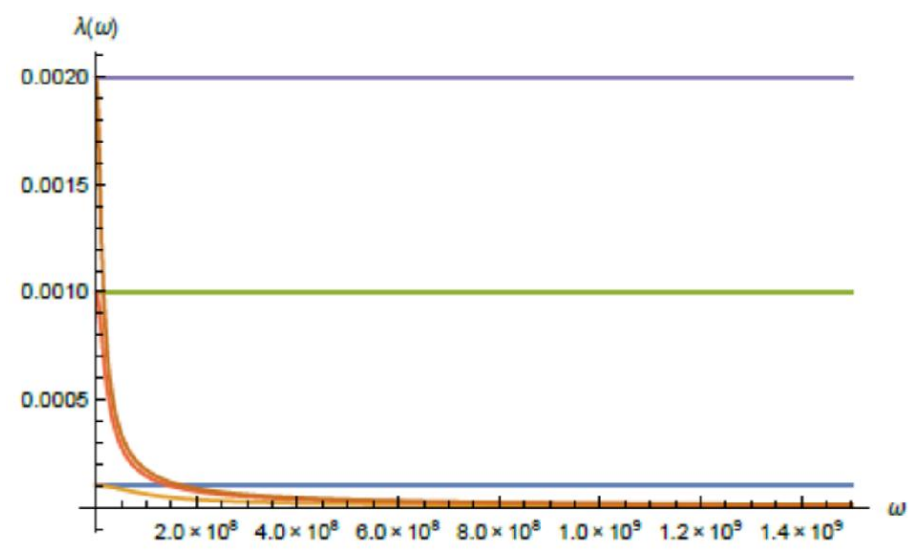

Fig. 4. The lengths of the formed waves in the interlayers in the case of high-frequency slow waves

Based on the convenience for a comparative analysis of the results, the numerical calculations are carried out for the same sets of materials of the waveguide cells for which the calculations were made in the case of the long-wave approximation.

In the considered case the lengths of the formed waves in the interlayers have the form which is specific for the high-frequency slow waves (Fig. 4). From the figure it is also obvious that short waves $\max _{n=0 ; 1 ; 2}\left\{\lambda_{n m}(\omega)\right\} \leq \min _{n=0 ; 1 ; 2}\left\{h_{n}\right\} \approx 10^{-4} m$ corresponding to the thicknesses of the layers of the waveguide are formed only at values higher than the frequency $\omega \approx 1.75 \times 10^{8}$ Hertz.

Substituting the solutions of equations (4.8), which correspond to the representation (4.9) and satisfy the condition (4.10), into the dispersion equations of channels (3.5) and into the relation (3.6) we find the bands of permissible (or forbidden) frequencies, as well as the admissible lengths of the propagating short wave for each channel (Fig.5.a, Fig.5b and Fig. 5.c) of the composite waveguide and also for whole waveguide (Fig.6). 

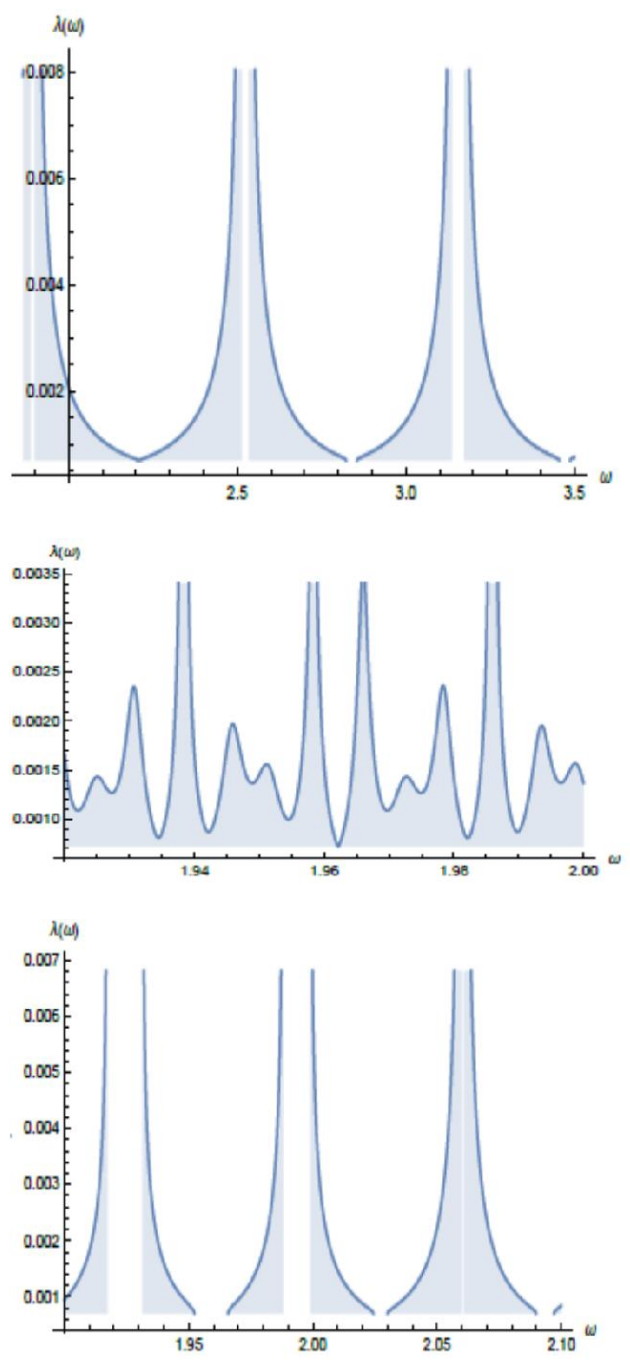

Fig. 5.a. Transmitting hard layer with parameters $\quad C_{21}=2.735 \times 10^{3} \mathrm{~m} / \mathrm{sec}$; $a=1.0 \times 10^{-2} \mathrm{~m} ; \quad C_{22}=2.326 \times 10^{3} \mathrm{~m} / \mathrm{sec} ;$ $b=2.5 \times 10^{-2} \mathrm{~m}$;

With soft cells in the interlayers $C_{01}=1.182 \times 10^{3} \mathrm{~m} / \mathrm{sec}$;

$C_{02}=1.67 \times 10^{3} \mathrm{~m} / \mathrm{sec} ; \quad$ Thinness of waveguide layers $h_{0}=1.0 \times 10^{-4} \mathrm{~m}$; $h_{1}=1 . \times 10^{-3} \mathrm{~m} ; h_{2}=2 . \times 10^{-3} \mathrm{~m}$;

Fig. 5.b. Transmitting soft and thin layer with parameters

$$
\begin{aligned}
& C_{01}=1.182 \times 10^{3} \mathrm{~m} / \mathrm{sec} ; \quad a=1.0 \times 10^{-2} \mathrm{~m} ; \\
& C_{02}=1.67 \times 10^{3} \mathrm{~m} / \mathrm{sec} ; \quad b=2.5 \times 10^{-2} \mathrm{~m} ; \\
& h_{0}=1.0 \times 10^{-4} \mathrm{~m} ; h_{1}=1 . \times 10^{-3} \mathrm{~m} ; \\
& h_{2}=2 . \times 10^{-3} \mathrm{~m} ;
\end{aligned}
$$

Fig. 5.c. Transmitting layer with parameters $C_{11}=2.326 \times 10^{3} \mathrm{~m} / \mathrm{sec} ; \quad a=1.0 \times 10^{-2} \mathrm{~m}$; $C_{12}=1.848 \times 10^{3} \mathrm{~m} / \mathrm{sec} ; \quad b=2.5 \times 10^{-2} \mathrm{~m}$;

With soft cells in the interlayers

$$
\begin{aligned}
& C_{01}=1.182 \times 10^{3} \mathrm{~m} / \mathrm{sec} ; \\
& C_{02}=1.67 \times 10^{3} \mathrm{~m} / \mathrm{sec} ;
\end{aligned}
$$

$$
\begin{array}{lr}
\text { Thinness of } & \text { waveguide layers } \\
h_{0}=1.0 \times 10^{-4} \mathrm{~m} ; & h_{1}=1 . \times 10^{-3} \mathrm{~m} ; \\
h_{2}=2 . \times 10^{-3} \mathrm{~m} ; &
\end{array}
$$

Fig.5. Zones of admissible and forbidden frequencies of high-frequency elastic shear waves in periodically longitudinally inhomogeneous layers of a composite waveguide

These calculations were carried out in the determination region of short-wave frequencies: $\omega \geq 1.85 \times 10^{8}$ Hertz. From Fig.5.a, Fig.5.b and Fig.5.c it follows that when the rigid cells (the lower layer in Fig.1.1) are adjacent, the bands of admissible frequencies are wide and separated from each other by relatively wide bands of forbidden frequencies (Fig.5.a).

In the case of a hard and soft neighboring cells (the upper layer in Fig.1.1), the bands of admissible frequencies are rather thin and separated from each other by relatively thin bands of forbidden frequencies (Fig. 5.c). In the case of two neighboring soft cells with the selected combination of materials and linear cell sizes, a continuous spectrum of admissible frequencies is obtained. Shorter wavelengths are passed through this channel. But in all these cases the propagation of short slow waves of length 
$\max _{n=0 ; 1 ; 2}\left\{\lambda_{n m}(\omega)\right\} \leq \min _{n=0 ; 1 ; 2}\left\{h_{n}\right\} \approx 10^{-4} m$ formed along the thickness of the waveguide is not allowed.

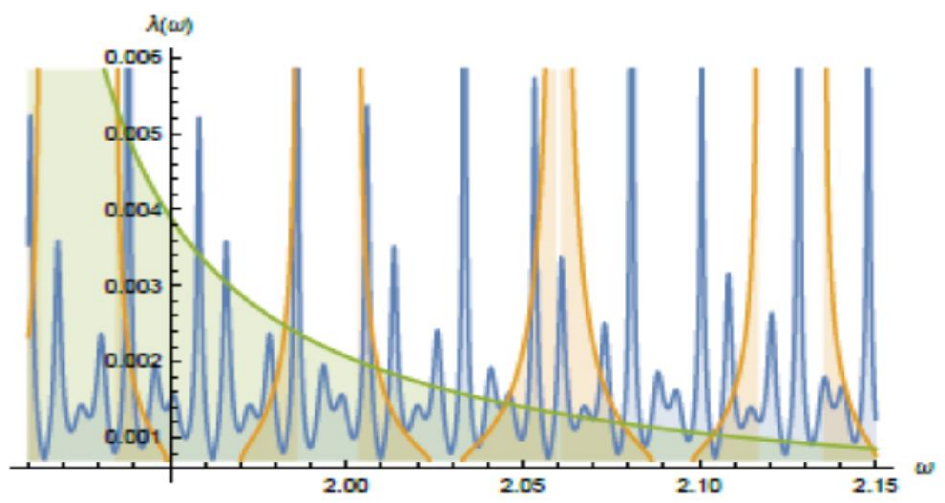

Fig.6. Zones of permissible and forbidden frequencies of high-frequency elastic shear waves in a periodically longitudinally inhomogeneous composite waveguide

The cross sections of the resulting zones of permitting frequencies along the waveguide channels (Fig.5.a, Fig.5.b, Fig.5.c) give the band of admissible frequencies and the corresponding lengths of admissible waves in the composite waveguide (Fig. 6).

From all these figures it is seen that along the thickness of a composite waveguide millimeter short waves of the length of the order $\lambda(\omega) \approx 1.0 \times 10^{-4} \mathrm{~m}$ can be formed. But the channels are allowed to propagate only waves of the length of the order $\lambda(\omega) \geq 5.0 \times 10^{-4} \mathrm{~m}$.

5. Conclusion. The cellular composite waveguide is modeled as a three-layer (threechannel), periodically longitudinally inhomogeneous waveguide of canonical rectangular cells.

The dispersion equations of wave transmission (filtering of frequencies) for each periodically inhomogeneous channel are derived.

In the case of propagation of a high-frequency (short-wave) wave signal of elastic shear and in the case of propagation of a low-frequency (long-wave) wave signal of elastic shear, the dispersion equations of wave formation in periodic composite layers of the waveguide were obtained and investigated.

The zones of admissible (or forbidden) frequencies are obtained both along the channels of the waveguide and in the whole waveguide from the dispersion equations of frequency filtration in accordance with the wave numbers in vertical composite layers.

The phonon structure of the constituent layers of the waveguide leads to different frequency transmission bands, forming a filter on separate layers, localizing the wave energy at the boundary segments of certain cells of the composite. It is shown that the formation along the waveguide thickness in periodic layers is determined by the physical-mechanical and linear parameters of the constituent cells of the interlayer.

The localization of the energy of an elastic shear wave (Love-type wave) at the boundaries of contiguous cells is characterized by the modules of physical constants of materials and the relative thicknesses of the constituent layers. 
In the process of filtering of the frequencies of the formed waveforms, the physicomechanical and linear parameters of neighboring cells of inhomogeneous channels play the determinative role.

\section{REFERENCES}

1. Rayleigh J.W. On waves propagated along the plane surface of an elastic solid. //Proc. Math. Soc. London. 1885/1886, vol.17, p.4-11.

2. Love A. E. H., «Some problems of geodynamics», first published in 1911 by the Cambridge University Press and published again in 1967 by Dover, New York, USA. (Chapter 11: Theory of the propagation of seismic waves).

3. Stoneley R. Elastic Waves at the Surface of Separation of Two Solids, Roy. Soc. Proc. London, ser. A 106, (1924), pp. 416-428.

4. Auld B.A., Surface acoustic waves and devices, Archives of Acoustics, (1991), vol.16, №1, pp. 11-30.

5. Achenbach J.D. Wave Propagation in Elastic Solids, Amsterdam, North-Holland, (1993), p.440.

6. Meleshko V.V., Bondarenko A.A., Dovgiy S.A., Trofimchuk A.N., van Heijst G.J.F. Elastic waveguides: History and the state of the art. I, (2009), vol.162, №1, pp. 99-120.

7. Gazalet J., Dupont S., Kastelik J.C., Rolland Q. and Djafari-Rouhani B. A tutorial survey onwaves propagating in periodic media: Electronic, photonic and phononic crystals. Perception ofthe Bloch theorem in both real and Fourier domains. Wave Motion, (2013), vol.50, p.619-654.

8. Hussein M.I., Leamy M.J., Ruzzene M. Dynamics of phononic paterialsand structures: historical origins, recent progress, and future outlook, Applied Mechanics Reviews, (2014), vol.66, pp.1-38.

9. Kaptsov A.V., Kuznetsov S.V., Love waves in a three-layer elastic semispace, Journal of Applied Mathematics and Mechanics, (2015), v.79, №4, pp.550-557 (in Russian). Капцов А.В., Кузнецов С.В. Волны Лява в трёхслойном упругом полупространстве // ПММ. 2015. Т.79. №4. С. 550-557.

10. Avetisyan A.S., Belubekyan M.V., Ghazaryan K.B. The Propagation of HighFrequency Shear Elastic Waves on Interface of Isotropic Elastic Half-Spaces with Canonical Surface Protrusions // American Journal of Earth Sci. and Eng. (2018), v.1, №2, pp.114-128, http://www.aascit.org/journal/ajese.

\section{Information about the authors:}

Ara S. Avetisyan - Department of Deformable Systems and Coupled Fields, Institute of Mechanics, National Academy of Sciences,

Yerevan-0019, Republic of Armenia, E - mail: ara.serg.avetisyan@gmail.com

Vazgen M. Khachatryan - Department of Deformable Systems and Coupled Fields, Institute of Mechanics, National Academy of Sciences,

Yerevan-0019, Republic of Armenia, E - mail: khachatryan-vazgen@inbox.ru

Received 04.04.2018 